\title{
HIV Medications as Drugs of Abuse
}

\author{
Glen P. Davis • Kristen Steslow
}

Published online: 23 May 2014

(C) Springer International Publishing AG 2014 emerging reports that ARVs are being diverted and used both as recreational drugs (alone or in combination with other substances) and as unmonitored treatment for HIV infection $[3,4 \cdot \bullet, 5 \bullet \bullet, 6 \bullet \cdot]$. Although most epidemiologic surveillance of prescription drug misuse focuses on medications with clearly understood abuse potential, such as opioid analgesics, stimulants, and sedatives [7], many medications affecting neural systems, including ARVs, have been identified as additional culprits for misuse [8].

The emergence of ARV misuse adds complex public health challenges to the existing landscape of HIV/AIDS treatment, addiction medicine, and psychiatry. Here, we present the available evidence of ARV diversion and misuse, explore the motives and consequences of such misuse, and discuss recommendations for further research and intervention.

\section{Antiretroviral (ARV) Diversion Discovered}

The development of antiretroviral (ARV) medication has dramatically reduced morbidity and mortality associated with human immunodeficiency virus (HIV) and acquired immunodeficiency syndrome (AIDS) [1]. Vigorous expansion in the global access to ARV medication, particularly within the past decade, has led to tremendous progress in stemming the HIV/ AIDS pandemic [2]. In recent years, however, there have been

G. P. Davis $(\bowtie)$

Department of Psychiatry - Division on Substance Abuse, Columbia University College of Physicians \& Surgeons, New York, NY, USA

e-mail: gpd2114@columbia.edu

G. P. Davis $\cdot$ K. Steslow

Janian Medical Care, P.C.,

Project for Psychiatric Outreach to the Homeless,

198 East 121st Street, 5th Floor, New York, NY 10035, USA

K. Steslow

e-mail: kks2140@columbia.edu
Diversion of ARV medication came to light in March 2007 when a group of researchers published a report in the journal Pain Medicine detailing interview results with drug-using, street-, and club-based populations in Miami [9]. The data confirmed that previously documented avenues, Internet sales, stolen shipments, "doctor-shopping" (patients gathering multiple prescriptions from different doctors), and unscrupulously prescribing physicians, were active channels for prescription drug diversion, but they also uncovered numerous largely unstudied street markets: patients trading (for illicit drugs) or selling legitimate prescriptions; healthy individuals being paid by pill brokers to defraud doctors; pharmacies buying back, then re-selling patients' medications; and burglaries and thefts at residences and pharmacies [9]. A few years later, fraud charges brought against doctors and pharmacies in New York confirmed that such markets existed in other large metropolitan centers [10-12]. 
While these markets alone were surprising, Inciardi et al. noted three particularly novel findings: 1) the development of the HIV-positive patient as a targeted prescription pill source, 2) the black market sale, theft, and trade of ARVs, and 3) the recreational use of ARVs [9]. Previous research had documented HIV-positive individuals supplying others with their own benzodiazepines and opioids, but this team observed trade in all HIV-positive patients' drugs, including their ARVs [9]. Further interviews reported pill brokers approaching HIVpositive patients at clinics, pharmacies, and support groups; pharmacists employing "spotters" to find HIV-positive patients with ARVs for resale; HIV-positive patients selling pills, or giving them away to those they felt were in greater need, taking only what remained; and illicit drug-using HIV-positive individuals being specifically targeted as low-price pill suppliers [9]. Inciardi et al. noted that diverted pills were ones patients did not like or ones with the highest value. HIVpositive individuals did not appear to understand the necessity of taking their entire medication cocktail [9].

In such a diversion, the buyer is not necessarily a pill broker. In fact, the HIV-positive informants noted that they more often purchased diverted HIV medications than sold, traded, or had them stolen [9]. While some purchases were to make up for selling too many pills when finances were limited, many black market purchases appeared because of a discomfort with serostatus disclosure [9]. Three years later, a South African ethnographic study uncovered a similar trend: interviews revealed off-label therapeutic use of ARV medication because of confidentiality concerns and mistrust of healthcare workers [13]. HIV-positive patients sold pills directly to other patients or to intermediaries who mirrored Miami’s pill brokers [13].

\section{Drivers of Diversion}

While stigma- and privacy-related fears are turning some HIVpositive individuals into black market customers, other factors appear to influence ARV diversion. In the Miami study, diversion-promoting factors included poor HIV-related health education, mistrust of the medical community, poverty, addiction to illicit substances, homelessness, and mental health issues [9]. The importance of such medical, economic, and psychosocial factors was confirmed quantitatively 6 years later. Among $503 \mathrm{HIV}$-positive individuals in South Florida, significant correlations were found between medication diversion and male gender, depression, anxiety, substance dependence, recent homelessness, and high HIV-related stigma. Non-diversion was associated with higher knowledge of HIV-related treatment, higher health literacy, and $95 \%$ ARV adherence [3]. While most of these correlations are intuitive, the relationship with male gender was not. However, more male participants reported recent homelessness, leading to the hypothesis that homelessness increased visibility as a target for pill brokers and indirectly increased diversion by male individuals [3]. Broadly speaking, high competing needs, psychosocial vulnerability, and low levels of HIV-related and general health education drive ARV diversion.

\section{Recreational ARV Use}

While many diverted medication end users are members of a local HIV-positive community, it is clear that diverted ARVs are also reaching a wider market. Some end users are not HIV positive, and their demand for ARVs is fueling a littleunderstood corner of the black market trade in HIV medications. Drawing on media reports of HIV medication diversion and confiscation from as early as 1999, Inciardi et al. listed the ARVs lamivudine/zidovudine, ritonavir, efavirenz, lopinavir/ ritonavir, and abacavir/lamivudine/zidovudine, and the nonARV (but commonly prescribed to HIV-positive patients) medications acetaminophen/oxycodone, somatropin, and dronabinol as reported targets, while their own interview data singled out ritonavir and efavirenz as common targets for Miami's pill brokers [9]. Informants in the study reported that ritonavir, a "booster" for other protease inhibitors, was being used to "boost" street drugs, especially methamphetamine and ecstasy, making ritonavir a valuable component in drug cocktails for recreational use [9]. Efavirenz was reportedly desired for its own intoxicating properties [9].

A handful of additional reports supporting claims of ARV misuse have since appeared in the scientific literature. In a South African qualitative study of substance abuse and HIV risk, three (of 22) interviewees spontaneously mentioned ARVs as a component in a recreationally smoked drug cocktail, though none reported personal use [5••]. In another qualitative study, eight (of 43) participants (interviewed about HIV treatment refusal) spontaneously discussed ARV abuse and diversion, though none reported personal use or explicit witnessing of others' use [6••]. To date, only one scientific report explicitly contains a second-hand description of ARV abuse (none contain first-hand, researcher-observed accounts). One of the (over 30) healthcare workers in the South African ethnographic study mentioned above described witnessing her boyfriend steal, crush, and smoke her efavirenz [13]. She reported not understanding his motive, because he had the economic means to buy other drugs [13].

\section{Enter the Media}

In 2009, media outlets began running reports of ARVs being crushed and smoked by South African adolescents [14-16]. Little further evidence regarding the manner of use or the ARVs' perceived psychoactive properties was published. 
While journalists speculated about the psychoactive and addictive properties of ARVs and the extent of their abuse, insufficient evidence was reported to extrapolate much reliable information from this series of articles.

The media articles, however, generated public fear of the addictive nature and social and health consequences of ARV abuse [13]. The rhetorical power of the recreational abuse of ARVs should not be understated. Nurturing the perception that diverted ARVs feed a rampant abuse trend may further stigmatize HIV treatment, legitimize treatment delays, and even threaten donations of ARV supplies [13].

\section{The Whoonga Controversy}

A later series of media reports inflamed public fear of ARV misuse by linking it to a street drug called whoonga, which has an established reputation as highly addictive and destructive in South Africa [17, 18]. Whoonga's contents are a source of disagreement. Media reports variously mention heroin, methamphetamine, rat poison, detergent, talcum powder, milk powder, baking powder, and crushed ARV pills, and informants commonly describe sprinkling the white powder into marijuana (dagga) or tobacco to smoke it $[16,17,19,20,21 \cdot$, $22,23]$. Thus, whoonga is likely to be a mixture of illicit and non-illicit substances whose precise contents are often unknown to users and may change depending on who is manufacturing the sample $[18,21 \bullet, 22]$. Such variation stems in part from manufacturers' practice of cutting in cheap and readily available substances as bulking agents, keeping the price of the drug low enough for its target market [18, 22]. With little more than rumor for evidence, media reports articulated growing public fear and indignation, which incited opposing calls for evidence-based and cautious reporting $[18,24]$. To this end, eight whoonga samples were chemically analyzed, six by a rehabilitation center director and two by an academic at a local university, and negative results were reported for ARV content [24].

Further details of the analyses were not published, but in a radio interview the chemist who analyzed two samples for investigative journalists reported they contained strychnine (rat poison) and opioids. Such content parallels addictive, white-powdered drug mixtures in South Africa commonly smoked with marijuana or tobacco and known by other names, notably the newer "nyaope" and the older "sugars" $[18,21 \cdot, 22,23]$. The similarity of these cocktails, and even the interchangeability of their names, lends credence to the hypothesis that "whoonga" may be a rebranded drug, following on the heels of heightened police crackdowns on the sugars trade $[22,23]$. The perception that ARVs are a key component of the powerful whoonga cocktail appears to increase its allure, regardless of its actual content $[18,23]$.
Indications that ARVs provide a powerful high also have the potential to drive ARV misuse independent of whoonga [24].

Intense stomach cramps, joint pain, and headaches have been consistently reported accompanying whoonga use [16, $17,21 \cdot, 22,23]$, suggesting that users may be experiencing opioid withdrawal $[5 \cdot \bullet]$ and opioids may be a common choice of base drug. Bulking agents may also serve a second purpose: the chemist who analyzed the first two whoonga samples hypothesized that the large amount of strychnine was responsible for the acute stomach pains that drive users to smoke whoonga so frequently $[22,23]$.

\section{A Role for Antiretrovirals in Whoonga?}

Complicating the picture, the media (and one scientific report) began conflating the practice of crushing and smoking ARVs (with marijuana or tobacco) with the purchasing and smoking (with marijuana or tobacco) of a manufacturer-created drug cocktail with unknown contents $[6 \bullet \bullet, 16,25,26]$. The difference is critical for scientists and journalists to maintain while mapping and analyzing emerging ARV abuse. The chemical makeup of whoonga and other such drug mixtures is likely inconsistent. While there is scant evidence that ARVs are currently added to whoonga, manufacturers of illicit drug cocktails in South Africa may find a use for the pills, whether as psychoactive or bulking components [18, 21•].

\section{Possible Mechanisms of Recreational ARV Effects}

In a 2013 review of emerging ARV abuse, Davis et al. synthesize the present state of the scientific understanding of the neuropsychiatric effects of ARVs, particularly efavirenz, and propose possible mechanisms of interaction between ARVs and common drugs of abuse [4••]. Tables 1 and 2 summarize their results.

ARV medications have central nervous system (CNS)stimulating effects, which are thought to be responsible for the neuropsychiatric complications documented in some HIVpositive patients taking ARVs [4.•]. In scattered case reports, some ARVs have been associated or suspected to be associated with delusions, hallucinations, and mania (zidovudine); mood changes and hallucinations (abacavir); psychosis and mania (nevirapine); and unspecified neuropsychiatric disorders (ritonavir) [4••]. The majority of neuropsychiatric effects have been associated with efavirenz, reported more frequently in patients with pre-existing psychiatric or substance use

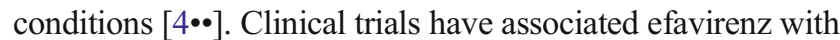
insomnia, dizziness, vivid dreams, and adverse psychiatric effects, while case and prospective studies have linked it with mania, depression, suicidal thoughts, hallucinations, and psychosis $[4 \bullet \bullet]$. It is possible that CNS stimulation is responsible 
Table 1 Potential interactions between ARVs and substances of abuse

\begin{tabular}{ll} 
Substance & Effect of Combination with ARVs \\
\hline Cannabis & $\begin{array}{c}\text { Combination with efavirenz may heighten the euphoria } \\
\text { of cannabis by CYP3A4 inhibition }\end{array}$ \\
Cocaine & No known effect in combination with ARVs \\
Heroin & No known effect in combination with ARVs \\
Oxycodone & $\begin{array}{c}\text { Enhanced effect in combination with ritonavir } \\
\text { by CYP2D6 inhibition }\end{array}$ \\
Methadone & $\begin{array}{c}\text { Opiate withdrawal in combination with efavirenz } \\
\text { or nevirapine by CYP3A4 induction }\end{array}$ \\
MDMA & $\begin{array}{c}\text { Enhanced effect of MDMA in combination with } \\
\text { ritonavir by CYP2D6 inhibition }\end{array}$ \\
Ketamine & $\begin{array}{c}\text { Enhanced psychogenic effect of ketamine in combination } \\
\text { with efavirenz and ritonavir by CYP2B6 inhibition }\end{array}$ \\
PCP & $\begin{array}{c}\text { Enhanced psychogenic effect of PCP in combination } \\
\text { with efavirenz or ritonavir by CYP3A4 inhibition }\end{array}$
\end{tabular}

Antiretroviral medication: an emerging category of prescription drug misuse. Am J Addict. 2013 Sep 17. doi: 10.1111/j.1521-0391.2013. 12107.x. [Epub ahead of print]. Copyright (C2013 American Academy of Addiction Psychiatry. This material is reproduced with permission of John Wiley \& Sons, Inc.

$A R V$ antiretroviral, $C Y P$ cytochrome $\mathrm{P} 450, M D M A$ methylenedioxymethamphetamine, $P C P$ phencyclidine

for recreational efavirenz effects, though its frequent coupling with marijuana also suggests an interaction with cannabis.

All of the ARV-illicit drug interactions proposed by Davis et al. result from ARVs' ability to inhibit enzymes involved in the metabolism of other drugs. When the un-metabolized form of the illicit drug is the more potent psychoactive molecule, such inhibition would yield higher concentrations of the un-metabolized substance in the user's bloodstream, increasing the illicit substance's psychoactive effects. Such effects were proposed for interactions between particular ARVs and cannabis, methylenedioxymethamphetamine (MDMA), methamphetamine, gamma-hydroxybutyric acid (GHB), and oxycodone [4••].

Table 2 ARV interactions with substances of abuse

\begin{tabular}{ll}
\hline ARV & Potential Interaction with Substances of Abuse \\
\hline Efavirenz & $\begin{array}{l}\text { Enhanced cannabis effect by CYP3A4 inhibition } \\
\text { Precipitated methadone withdrawal by CYP3A4 induction }\end{array}$ \\
Ritonavir & $\begin{array}{l}\text { Enhanced oxycodone effect by CYP2D6 inhibition } \\
\text { Enhanced MDMA effect by CYP2D6 inhibition }\end{array}$ \\
& $\begin{array}{l}\text { Enhanced GHB effect by CYP inhibition } \\
\text { Nevirapine }\end{array}$ \\
Precipitated methadone withdrawal by CYP3A4 induction
\end{tabular}

Antiretroviral medication: an emerging category of prescription drug misuse. Am J Addict. 2013 Sep 17. doi: 10.1111/j.1521-0391.2013. 12107.x. [Epub ahead of print]. Copyright (C2013 American Academy of Addiction Psychiatry. This material is reproduced with permission of John Wiley \& Sons, Inc.

$A R V$ antiretroviral, $C Y P$, cytochrome $\mathrm{P} 450, G H B$ gamma-hydroxybutyric acid, $M D M A$ methylenedioxymethamphetamine
In the short term, efavirenz inhibits cytochrome P450 (CYP)3A4, which metabolizes marijuana's primary psychoactive components ( $\Delta^{8}$-THC, $\Delta^{9}$-THC, and metabolites), theoretically maintaining higher serum concentrations of these un-metabolized molecules $[4 \bullet \cdot]$. (Efavirenz also induces CYP3A4, but the inductive action occurs over the course of days or weeks $[4 \cdot \bullet]$.) While efavirenz is the ARV featured in reported combinations with marijuana, ritonavir (like all protease inhibitors) also inhibits CYP3A4 [4••], so the proposed metabolic effects of efavirenz on marijuana should be producible by ritonavir or any other protease inhibitor. Efavirenz's additional neuropsychiatric effect may account for its favor. In a manner similar to the interaction with cannabis, inhibition of CYP3A4 may inhibit cocaine metabolism, but because only $10 \%$ of cocaine metabolism involves a CYP3A4 pathway, efavirenz and other protease inhibitors are not expected to have a large enough impact to increase serum concentrations of cocaine $[4 \cdot \bullet]$.

Ritonavir and saquinavir were hypothesized to use the same pattern of metabolism inhibition to increase serum concentrations of GHB, also through inhibition of the CYP450 system involved in first-pass GHB metabolism [4・•]. MDMA and methamphetamine metabolisms involve CYP2D6, which is strongly inhibited by ritonavir, leading to a potentially acute increase in MDMA serum concentrations (and psychoactive effects). This hypothesis is suggested by the abnormally high MDMA serum concentration detected in the autopsy of a 32year-old, HIV-positive man who took $180 \mathrm{mg}$ of MDMA while on a regimen including ritonavir [4••]. CYP3A4 is also involved in MDMA metabolism, so efavirenz, ritonavir, and other protease inhibitors would also be expected to inhibit MDMA breakdown through this pathway, but it is unclear whether the effects would be pronounced enough to increase serum drug concentrations $[4 \bullet \bullet]$. Ritonavir's weak inhibition of CYP2D6 should theoretically increase the serum concentrations of oxycodone $[4 \cdot \bullet]$.

When the more potent psychoactive molecule is a metabolite of an illicit substance, inhibiting a protein involved in metabolism of a drug would be expected to result in decreased serum concentrations of the more psychoactive molecule. In the case of existing addiction, this might result in a withdrawal effect $[4 \cdot \bullet]$. Such withdrawal-inducing interactions have been proposed between ARVs and methadone or hydrocodone. Ritonavir inhibits CYP2D6, which metabolizes hydrocodone to the more potent hydromorphone $[4 \bullet \cdot]$. Hydrocodone is also metabolized by CYP3A4, but the dominant effect is expected to decrease serum concentrations of hydromorphone, which may lead to withdrawal in the case of existing opioid addiction [4.•]. A parallel induction of opioid withdrawal is expected in the combination of protease inhibitors (efavirenz and nevirapine are mentioned specifically) and methadone, because methadone metabolism is largely conducted by CYP3A4 $[4 \bullet \bullet]$. No evidence or plausible interaction mechanisms have 
been reported for the combination of ARVs with buprenorphine, heroin, morphine, or codeine.

\section{Consequences of Off-label ARV Use}

Black market demand for ARVs may increase the risk of theft of these medications, jeopardizing the safety of patients targeted for their pills [9, 24]. ARV diversion might also alter perceptions of the abuse potential for ARVs, potentially leading to unnecessary regulation of these medications and further restricting access among those who need treatment [13, 24]. Therapeutic end use of diverted ARVs may not follow standard treatment guidelines, resulting in patients with inadequate treatment and less controlled illness [9, 13, 27]. Perhaps the most alarming risk of off-label ARV use, however, is its potential to foster resistant HIV strains. In 2011, researchers investigating ARV treatment resistance in Mwanza, Tanzania discovered dramatically high levels of resistance among 88 self-declared, treatment-naive patients [27]. Kasang et al. proffered two possible means of developing such resistance: direct sexual transmission of drug-resistant viruses or "selection from the natural pool of quasispecies in each individual patient following undisclosed antiretroviral drug experience" [27]. While their analyses suggested that most of the mutations were due to transmission, the researchers detected traces of ARVs in the plasma samples of two patients, indicating that these patients had used ARVs within the 1- to 2-week window detectable by the test and had not told the researchers. Kasang et al. concluded that at least some of the treatment resistance was likely due to off-label ARV use, and they hypothesized that self-medication was a likely culprit [27]. Resistance means a diminished effective pharmaceutical armament against HIV, for individuals and for populations [27]. Fewer effective medications, in turn, threaten global efforts to contain this epidemic [27].

\section{Conclusion}

There are plausible mechanisms by which ARVs may enhance the effects of illicit drugs [4••]. Enhancing combinations include cannabis with efavirenz and ritonavir with MDMA, methamphetamine, GHB, or oxycodone [4••]. In addition, evidence exists that efavirenz may have independent psychoactive properties [4••]. These actions and interactions mirror the existing evidence of ARV abuse patterns: efavirenz smoked with marijuana in South Africa and desired in Miami for its own psychoactive effects, and ritonavir used as a "booster" for ecstasy (MDMA) and methamphetamine.

Depending on the contents of whoonga, a South African drug cocktail, ARVs may or may not be active if added to the mixture. Because whoonga is reportedly cut into marijuana and smoked, it is plausible that efavirenz could boost the marijuana high and/or provide its own psychoactive action. Whoonga use in existing reports, however, is described as an intense, opioid-like pain relief and high, followed by symptoms reminiscent of opioid withdrawal $[14,18,19,23 \bullet, 24$, $25]$. No interactive mechanisms were uncovered involving ARVs with heroin, morphine, or codeine-opioid components found in two samples of whoonga-or with buprenorphine [4••]. The only opioid-boosting mechanism proposed involved ritonavir (not described in whoonga reports), and oxycodone [4••]. Methamphetamine is a common drug of abuse in South Africa [28], and if a drug cocktail such as whoonga contained it, the addition of ritonavir could conceivably boost the mixture's effects.

Any off-label ARV use has the potential to create resistant HIV strains, diminishing the effectiveness of currently available drugs [27]. The black market trade in ARVs may also alter public perception of the abuse potential of these drugs, creating supply restrictions and other barriers to treatment $[13,24]$. Not all black market trade, however, is abuse driven: significant portions of the market are occupied by off-label therapeutic use $[9,13]$. Black market sales of ARVs to areas with little available HIV treatment indicate that a legitimate need for medication coupled with inadequate healthcare fuels ARV diversion [11]. The sale and trade of ARVs in local HIV-positive communities constitutes another significant market component, driven by psychosocial factors including high competing needs, stigma, distrust, and poor health-related education [3, 9, 13].

Further research is needed to demystify the nature and scope of ARV abuse potential. Epidemiologic surveillance is warranted to establish the extent of antiretroviral diversion and misuse and characterize those who are most at risk for misusing these medications. Abuse liability testing in the laboratory is needed to illuminate the euphorigenic effects of ARVs among drug users and further understand the emerging problem of ARV misuse. Psychosocial and health-disparityrelated ARV diversion is fueling a significant component of the ARV black market and might be inflating off-label ARV use, contributing to risks of developing resistant HIV strains. Psychosocial factors and health disparities are known enemies in the fight against HIV, and they are amenable to existing interventions. It is recommended that resources be directed toward the most effective of these known interventions to significantly diminish the black market trade in ARVs and stem the serious consequences of off-label ARV use.

\section{Compliance with Ethics Guidelines}

Conflict of Interest Kristen Steslow and Glen Davis declare that they have no conflicts of interest.

Human and Animal Rights and Informed Consent This article does not contain any studies with human or animal subjects performed by any of the authors. 


\section{References}

Papers of particular interest, published recently, have been highlighted as:

- Of importance

-. Of major importance

1. Ford N, Vitoria M, Hirnschall G, Doherty M. Getting to zero HIV deaths: progress, challenges, and ways forward. J Int AIDS Soc. 2013;16:18927.

2. HIV/AIDS: data and statistics. Geneva: World Health Organization. 2014. Available from: http://www.who.int/hiv/topics/treatment/ data/en/index1.html. Accessed 3 May 2014.

3. Surratt HL, Kurtz SP, Cicero TJ, et al. Antiretroviral medication diversion among HIV-positive substance abusers in south Florida. Am J Public Health. 2013;103(6):1026-8.

4.• Davis G, Surratt H, Levin F, et al. Antiretroviral medication: an emerging category of prescription drug misuse. Am J Addict. 2013. doi:10.1111/j.1521-0391.2013.12107.x. Review article detailing the emerging problem of ARV diversion and misuse with discussion of pharmacodynamic interactions between ARVS and illicit substances.

5.• Grelotti D, Closson E, Smit J, et al. Whoonga: potential recreational use of HIV antiretroviral medication in South Africa. AIDS Behav. 2013. doi:10.1007/s10461-03100575-0. Qualitative study of whoonga use, with potential ARV content, among clubbing youth in Durban, South Africa.

$6 . \bullet$ Rough K, Dietrich J, Essien T, et al. Whoonga and the abuse and diversion of antiretrovirals in Soweto, South Africa. AIDS Behav. 2013;1:1-3. Qualitative results from semi-structured interviews of residents in Soweto, South Africa, characterizing diversion and recreational use of ARV medications there.

7. Johnston LD, O'Malley PM, Bachman JG, Schulenberg JE. Monitoring the future national survey results on drug use, 19752010. Volume II: college students and adults ages 19-50. Ann Arbor: Institute for Social Research, The University of Michigan; 2010.

8. Caplan JP, Epstein LA, Quinn DK, et al. Neuropsychiatric effects of prescription drug abuse. Neuropsychol Rev. 2007;17(3):36380 .

9. Inciardi JA, Surratt HL, Kurtz SP, et al. Mechanisms of prescription drug diversion among drug-involved club- and street-based populations. Pain Med. 2007;8(2):171-83.

10. United States Attorney's Office, Southern District of New York. Manhattan doctor pleads guilty to $\$ 8.5$ million Medicare fraud scheme. Press release. February 25, 2013. http://www.justice.gov/ usao/nys/pressreleases/February13/AymatRobertoPlea.php. Accessed 18 Apr 2014.

11. Wright K. Psst, got antiretrovirals? Mother Jones. May/June 2007. http://www.motherjones.com/politics/2007/05/psst-gotantiretrovirals. Accessed 17 Apr 2014.

12. Slattery D. Bronx pharmacy owners, druggist busted in $\$ 10$ million AIDS medication scam: authorities. Daily News. March 11, 2014. http://www.nydailynews.com/new-york/bronx/bronx-pharmacistbusted-article-1.1717890. Accessed 17 Apr 2014.
13. Larkan F, Van Wyk B, Saris J. Of remedies and poisons: recreational use of antiretroviral drugs in the social imagination of South African carers. Afr Sociol Rev. 2010;14(2):62-73.

14. Ballantyne C. HIV drugs turned street drugs in South Africa. April 7, 2009. http://www.scientificamerican.com/blog/post.cfm?id=hivdrugs-turned-street-drugs-in-so-2009-04-07. Accessed 15 Apr 2014.

15. Sciutto J. 'No turning back': teens abuse HIV drugs. April 8, 2009. http://abcnews.go.com/Health/MindMoodNews/story?id= 7227982\&page=1. Accessed 15 April 2014.

16. Fihlani P. "Whoonga" threat to South African HIV patients. BBC News 2011. http://www.bbc.co.uk/news/world-africa-12389399. Accessed 24 Oct 2011.

17. Sparks C. Addictive drug threatens the future of South African youth. Media Global News. March 15, 2011. http://www. mediaglobal.org/2011/03/15/addictive-drug-threatens-the-futureof-south-african-youth/. Accessed 17 Apr 2014.

18. Botmi A. Urban legend takes on life of its own. Independent online. March 22, 2011. http://www.iol.co.za/scitech/science/news/urbanlegend-takes-on-life-of-its-own-1.1045056\#.U07ej-ZdVSQ. Accessed 15 Apr 2014

19. Ho U. Cheap high is taking families down. IOL News. May 2, 2013. http://www.iol.co.za/news/crime-courts/cheap-high-istaking-families-down-1.1509616\#.U11fheZdXjQ. Accessed 27 Apr 2014.

20. Boomgaard M. Whoonga whammy. IOL News. November 8, 2012. http://www.iol.co.za/news/south-africa/kwazulu-natal/whoogawhammy-1.878484\#.U157ouZdXjQ. Accessed 28 Apr 2014.

21. Mceachran R. In South Africa, a deadly new drug is made with HIV medications. The Atlantic. August 27, 2013. http://www.theatlantic. com/international/archive/2013/08/in-south-africa-a-deadly-newdrug-is-made-with-hiv-medications/278865/. Accessed 17 Apr 2014. A recent example of media coverage implicating ARVs in street drug cocktails in South Africa.

22. Chapman S. Rat poison and heroin. Mahala. September 18, 2013. http://www.mahala.co.za/reality/rat-poison-and-heroin/. Accessed 16 Apr 2014.

23. Kelto A. Heroin's handmaiden. Dispatches. Canadian Broadcasting Company. February 24, 2011. http://www.cbc.ca/video/news/ audioplayer.html?clipid=1814719941. Accessed 15 Apr 2014.

24. Analysis IPGHANa. South Africa: No ARVs in 'whoonga' say experts. February 10, 2011.

25. Knox R. Dangers of 'whoonga': abuse of AIDS drugs stokes resistance. Shots: Health news from NPR. December 18, 2012. http://www.npr.org/blogs/health/2012/12/18/167523601/dangersof-whoonga-abuse-of-aids-drugs-stokes-resistance. Accessed 17 Apr 2014.

26. Daily mail reporter. Addicts mix HIV drugs with marijuana in South Africa's deadly new 'whoonga' craze. November 21, 2010. http://www.dailymail.co.uk/news/article-1331712/Whoonga-drugnew-twist-South-Africas-war-AIDS.html. Accessed 17 Apr 2014.

27. Kasang C, Kalluvya S, Majinge C, et al. HIV drug resistance (HIVDR) in antiretroviral therapy-naïve patients in Tanzania not eligible for WHO threshold HIVDR survey is dramatically high. PLos One. 2011;6(8):1-11.

28. Plüddemann A, Dada S, Parry C, et al. Monitoring alcohol and drug abuse trends in South Africa (July 1996-June 2008): phase 24. SACENDU Res Brief. 2008;11:1-12. 